This document is published in:

Regional Science and Urban Economics (2006), 36(1), 132-157. DOI: 10.1016/j.regsciurbeco.2005.07.001

(C) 2005 Elsevier B.V. 


\title{
A theoretical model of nations, regions and fiscal integration
}

\author{
Ignacio Ortuño-Ortín $^{\mathrm{a}, *}$, Jaume Sempere ${ }^{\mathrm{b}}$ \\ ${ }^{\text {a }}$ Department of Economics, University of Alicante and IVIE, 03080-Alicante, Spain. \\ ${ }^{\mathrm{b}}$ El Colegio de México, Mexico
}

\begin{abstract}
This paper analyzes how the incentives of regions differ from those of nations when choosing a supranational fiscal arrangement. Two types of fiscal arrangements are studied: a Union of nations and a Federation of nations. Under the Union, there is full fiscal integration, and under the Federation, there is only partial fiscal integration and partial insurance against local risks. We show that the claim that regions have stronger incentives than nations to form a supranational Union rather than a Federation might be true only in the case where regions have strong incentives to be part of a centralized nation.
\end{abstract}

JEL classification: $\mathrm{H} 11 ; \mathrm{H} 77 ; \mathrm{H} 87$

Keywords: Federalism; Fiscal coinsurance; Migration

\section{Introduction}

In the last decades Europe has gone through a process of increased integration among nations and, at the same time, many of those nations have been implementing reforms that increase the autonomy of their regions. In Belgium, Italy, Spain, and the United Kingdom there are political parties asking for more autonomy (and even secession) of regions. The

\footnotetext{
* Corresponding author. Fax: +34 965903898.

E-mail address: ortin@merlin.fae.ua.es (I. Ortuño-Ortín).
} 
common view that the recent emergence of nationalistic parties is the response of the rich regions to their "exploitation" by the poor ones is not completely convincing. This being because such abuses have a long history. ${ }^{1}$ An alternative interpretation is that, with unified markets, rich regions have more interaction with the rest of Europe and less with other regions in their countries. A larger market increases the set of possible coalitions with whom regions can interact and might cause the break-up of the old coalitions. ${ }^{2}$

That more integration can induce more autonomy is a phenomenon that has been studied in the theoretical literature. ${ }^{3}$ A theoretical question that has not been studied is whether increasing autonomy of the regions can reinforce or not the integration process. In other words, whether giving to the regions enough autonomy and political decision power would result in an agreement implying different levels of integration than those resulting in economies where centralized nations were the decision makers.

In this paper we focus on how the incentives of regions differ from those of nations when choosing a type of common fiscal arrangement. We will consider a very simple but, we hope, relevant and clarifying environment with only two nations. Each nation will consist of two regions. Two types of fiscal arrangements will be considered: One implying more fiscal integration than the other. We call them (following Bucovetsky, 1998) a Union and a Federation. ${ }^{4}$ Under a Union the transfers from poor areas to rich areas are such that all the participants end up with the same income level. Thus, this type of unitary fiscal arrangement would bring full insurance against local shocks for all the nations (and for the regions forming the nations). ${ }^{5}$ Under a Federation, however, there are no transfers from poor to rich areas but citizens are free to migrate within the area forming the Federation. Thus, under a federal system, risk-sharing is achieved by means of migration from poor areas to richer areas. Since migration is costly a federal system provides only partial insurance against local risks. ${ }^{6}$

We also consider two types of institutional scenarios depending on whether the decision makers are the nations or the regions. In the first case, nations are the relevant political actors and the regions constituting a nation have no influence on the decision on forming a possible supranational fiscal arrangement. A nation here is the result of the fiscal and political union of its two regions and, consequently, the national government represents the aggregated interests of the citizens from such regions. In the second scenario, regions are seen as the relevant independent decision makers. This could be the case of some very decentralized countries where regions enjoy a high degree of economic autonomy and political power. It is often the case that regions in a decentralized nation, in addition to having their own governments, have also direct representatives on a national body such as a Senate. In this case, some national policies, as for example joining a supranational fiscal union, require the approval of the regions.

\footnotetext{
${ }^{1}$ However, in many former socialist European economies, those regional differences are more recent. See Berkowitz (1997) for an analysis and empirical evidence of the regional secessionist pressures in those countries.

${ }^{2}$ See, for example, Casella (2001).

${ }^{3}$ See, for instance, Alesina and Spolaroe (1997) and Casella (2001).

${ }^{4}$ However, they do not intend to represent real federations or unions. This is only a way to put names to agreements implying different fiscal integration levels.

${ }^{5}$ We abstract from the political risk discussed, for instance, in Alesina and Perotti (1998).

${ }^{6}$ In our model taxation is not distortionary and there are no moral hazard problems of the type analyzed in Persson and Tabellini (1996a,b). Thus, tranfers between areas are not costly. This assumption can be relaxed as long as migration is more costly than transfers.
} 
The question we want to explore is whether the institutional scenarios defined above are important or not to understand the degree of supranational fiscal integration. Put in more explicit terms, the question is if the degree of fiscal autonomy and political power of regions is important to determine the type of international fiscal agreement that would be achieved.

One might think that autonomous regions, being smaller economic areas than nations, are exposed to higher risks and as a consequence have stronger incentives, as compared to nations, to form a Union. A nation, on the other hand, might prefer the partial insurance mechanism provided by the Federal system since it faces a lower risk and the full insurance associated with a supranational Union might be "too costly". Notice that if a Union of nations is formed the rich nation will have to give transfers to the poorer nation. It might happen that the level of such transfers is so high that the rich nation prefers not to joining the Union and bear the risk of becoming the poorer nation in the future and, in that case, not receiving transfers from the other nation.

We will show, however, that the previous intuition might be quite misleading. Suppose that one of the two nations is richer than the other in expected terms and, in the same way, within each nation one region is richer than the other. Thus, suppose that different nations, and different regions, each face different idiosyncratic risks. It is true that the regions, as independent economic areas, might face higher risks than they would if they were a fully integrated part of a nation. But now the income dispersion among the four regions is also higher than the income dispersion between the two nations. In this case, the richest region might find the partial insurance arrangement associated to a Federation more profitable than a unitary fiscal arrangement and at the same time, were nations the players, both nations would prefer the full insurance associated with the unitary agreement to the insurance provided by the federal system. This could happen when the cost of forming a Union, in terms of the implied expected redistribution, is higher for the richest region - in the case of fiscally autonomous regions - than for the richest nation - in the case of centralized nations.

The relevance of our analysis rests on the assumption that nations (or regions) cannot obtain full insurance against idiosyncratic shocks in the market. Thus, in our approach, the Union and the Federation can be seen as institutions that offer the risk-sharing that is not provided by the market. We believe that, as first pointed out empirically by Sala-i-Martin and Sachs (1992) and von Hagen (1992) who evaluate the risk-sharing provided by the fiscal system in the US, this might be seen as a realistic assumption. ${ }^{7}$

\footnotetext{
7 The empirical estimates of risk sharing via the fiscal system in the US vary from $10 \%$ to $13 \%$ in von Hagen (1992) and Asdrubali et al. (1996), to a 40\% estimated by Sala-i-Martin and Sachs (1992). In a recent contribution, Melitz and Zumer (2002) explain this huge difference in that Sala-i-Martin and Sachs use personal income concepts and also a broad measure of net transfers, wheras von Hagen uses gross product concepts with a narrow concept of net tranfers. On the other hand, Melitz and Zumer contribute to this literature by disentangling risk sharing and redistribution via the fiscal system. Regarding the European Union, Sorensen and Yosha (1998) estimate that a lot less risk sharing is achieved within countries in the European Union than within the United States. On the other hand, Obstfeld (1994), Shiller and Athanasoulis (1995), Athanasoulis and von Wincoop (1998), and van Wincoop (1999) provide empirical estimations of potential welfare gains from international and interregional risk-sharing above those not provided by the market. Forni and Reichlin (1999) provide some measures of the potential insurable risk for the European countries. In addition to these empirical papers, there are many recent theoretical models where the motive for integration is risk sharing, see, for instance, Alesina and Perotti (1998), Persson and Tabellini (1996a,b) and Wildasin (1995, 2000).
} 
One additional question to assess the merit of the analysis provided in this paper is whether migration is, in reality, an important way to share risks among nations or regions. Barro and Sala-i-Martin (1991, 1992) provide evidence of the relationship between migration flows to US states and per capita income. Blanchard and Katz (1992) also show that migration is an important insurance device against regional business cycle shocks. Eichengreen (1993) finds a strong relationship between migration and the lagged growth rate of wages in the US.

Closely related to this paper is the approach taken by Bucovetsky (1998), who compares the incentives for two geographic areas to choose a federal state agreement versus a unitary state. In this paper, geographic areas suffer stochastic idiosyncratic shocks and so the motive for the agreement is to provide insurance. The important parameters to take into account are related to risk aversion, differences in expected income, and migration costs.

Neither of the referred papers, however, analyzes the issue considered in our model: the different incentives between regions and nations regarding supranational fiscal arrangements.

The paper is organized as follows. Section 2 presents the model. Section 3 presents the different type of agreements to be considered. Section 4 shows some results that will be useful for the proof of the main proposition. Section 5 discusses our main result. Section 6 concludes the paper with some final remarks. Finally an Appendix presents the proofs of our results.

\section{The model}

Our model shares its basics features with the model developed in Bucovetsky (1998) with the difference that we will consider two possible levels of decision. The national level is modeled exactly as in Bucovetsky's, but in this paper each nation consists of two regions which face idiosyncratic regional shocks.

We will consider two nations, $\mathrm{A}$ and $\mathrm{B}$. A consists of two regions $\mathrm{A} 1$ and $\mathrm{A} 2$, and $\mathrm{B}$ consists of regions $\mathrm{B} 1$ and $\mathrm{B} 2$ (sometimes we write $R_{j}$ to denote the region $j$ of nation $R$, $j \in\{1,2\}, R \in\{\mathrm{A}, \mathrm{B}\})$. We normalize population so that the number of people in each region is $1 / 2$. So each nation's total population is 1 .

There is uncertainty about the national production level (which will be also given in per capita terms, given our normalization). It can be either $\rho$, if the good state of nature happens in that nation, or 1 if the bad state occurs, where $\rho>1$. We assume that national production levels are negatively correlated, i.e. if one nation gets the good state of nature then the other nation obtains the bad state of nature. We make this assumption in order to concentrate our analysis on the possible risk-sharing advantages of forming a union. ${ }^{8}$ The good state of nature occurs in nation A with probability $\pi$ (so the good state of nature

\footnotetext{
${ }^{8}$ Obviously, a more realistic assumption would be that shocks can go in any direction. However, if we do not consider negatively correlated shocks there would be no point of talking about risk sharing. A more general assumption that gives the same results would be that on top of the more general shocks there are important shocks that are negatively correlated.
} 
occurs in $\mathrm{B}$ with probability $1-\pi)$. We assume that $\pi>1 / 2$ so country $\mathrm{A}$ is richer than country B in expected terms.

We also assume that regional idiosyncratic shocks can happen. These shocks are such that they add the amount $\gamma / 2$ to the production level in a lucky region and reduce the production level by $\gamma / 2$ in an unlucky one. We assume that within either nation there is a perfect negative correlation between the regional shocks so that when region $R 1$ gets a positive (negative) shock region $R 2$ gets a negative (positive) shock. This implies that a lucky region in a lucky nation (from now on, in the state $\mathrm{HH}$ ) will have the total production

$$
Y_{\mathrm{HH}}=\frac{\rho+\gamma}{2} .
$$

A unlucky region in a lucky nation (state HL) would have

$$
Y_{\mathrm{HL}}=\frac{\rho-\gamma}{2} \text {. }
$$

A lucky region in an unlucky nation (state LH) would have

$$
Y_{\mathrm{LH}}=\frac{1+\gamma}{2}
$$

And, finally, an unlucky region in an unlucky nation (state LL) would have

$$
Y_{\mathrm{LL}}=\frac{1-\gamma}{2}
$$

Region $R 1, R \in\{\mathrm{A}, \mathrm{B}\}$, is lucky with probability $p$ (so region $R 2, R \in\{\mathrm{A}, \mathrm{B}\}$, is lucky with probability $1-p$. We assume that $p \geq 1 / 2$ so $\mathrm{A} 1$ and $\mathrm{B} 1$ are the rich regions (in expected terms) in nations A and B, respectively. We will interpret A1 and B1 as the North in each nation and A2 and B2 as the South. Note that the probability $p$ is the same in both nations. These regional production levels are consistent with the national ones defined previously. Notice that the unlucky region in the lucky nation might have a greater or lower income (and per capita income) than the lucky region in the unlucky nation. ${ }^{9}$

It is assumed that in an economy with centralized nations each nation is formed by the Union of its two regions. In this case, the central government implements the level of interregional transfers that achieve full equalization of income across regions. Thus, in the economy with centralized nations, the regional shocks will not be relevant.

\footnotetext{
${ }^{9}$ Empirically, the income of the richest region in the South will be greater or lower than the income of the poorest region in the North depending on how the North and South are aggregated within each nation. For instance (see graph 5.3 in Esteban, 1994), in 1989, (taking 100 as the average per capita income in the European Union), $40 \%$ of the population in Spain lived in regions having a per capita income between 110 and 80 . This would be the North of Spain. 55\% of the population of France live in regions that had per capita income above 100. This could be the North of France in our model. The South of France would be the $45 \%$ living in regions that have a per capita between 100 and 80 (thus providing a high degree of overlap with the North of Spain). The South of Spain would be the $60 \%$ living in regions having a per capita income lower than 80 . Similar considerations could be used to construct the North and South of the respective Northern and Southern countries. However, in Greece and Portugal, all regions have per capita incomes lower than the poorest region in several Northern countries.
} 
We assume that all agents of a given nation or region are identical to each other. In this case, the preferences of a nation $R$ and the preferences of a region $R_{j}$, coincide with the individual preferences of their members.

(A.1). All regions and nations share the same von Neuman Morgenstern concave utility function $U$ with per capita income as the argument. This utility function presents constant relative risk aversion. Thus we can write $U(x)=\frac{x^{1-\beta}}{1-\beta}, \beta>0$, where $x$ is per capita income. $^{10}$

The total resources in a region are distributed equally among all the residents so that the per capita income is the same for all of them. Since in a centralized nation the income in both regions is the same, citizens have no incentives to migrate to the other region in the nation. Under a decentralized nation with fiscally autonomous regions, however, the two regions will have different income levels. Thus, in the decentralized case, an agent that migrates from a poor region to a richer region, within the same nation, would obtain a higher income than an agent who remains in the poor region. The same thing happens when migration takes place from the poor region of a nation to a richer region in a different nation. There is, however, a positive migration cost.

(A.2). There is a constant individual cost $c \geq 0$ of migrating from one region to another. This cost is the same whether the migration takes place within a nation or from a region in a nation to a region in a different nation.

This is clearly a strong assumption but our results are robust to small changes allowing for lower migration cost within a nation than across nations. ${ }^{11}$ In fact, we could allow for large differences in the migration costs as long as the income dispersion between regions is large enough. Nevertheless, in order to keep things simple, we will assume (A.2) throughout the paper.

Following Bucovetsky (1998) we define a Federal fiscal agreement (or a Federation) as one in which there is free migration among the nations or regions involved, but no transfers to equalize per capita income among the different areas. A Unitary fiscal agreement (we also call it a Union) is the one in which a central authority uses transfers to equalize per capita income in the different areas and, consequently, there is no migration.

We will consider two types of environments depending on whether the decision makers are the regions or the nations. The idea is that, in very centralized nations, where there is already an economic union among the two regions and a powerful central government, the decision maker is the "nation". In decentralized nations, with high levels of political and economic regional independence, the decision makers are the regions. The four types of agreements we analyze are : (i) a union of nations A and B (UN); (ii) a federation of nations $\mathrm{A}$ and $\mathrm{B}(\mathrm{FN})$; (iii) a federation of regions A1, A2, B1 and B2 (FR); and (iv) a union of regions $\mathrm{A} 1, \mathrm{~A} 2, \mathrm{~B} 1$ and $\mathrm{B} 2$ (UR). In cases i) and ii) the decision makers are the

\footnotetext{
${ }^{10}$ This assumption is also made in Bucovetsky.

11 If the cost of migrating to other region within a nation is very small then there is no point in comparing the economy with regions with the economy with nations. Trivially, free migration with very low migration cost between regions in a nation will make each of the regions in each nation share (almost) the same income and therefore they will behave as nations.
} 
nations meanwhile in cases iii) and iv) the decision makers are the regions. We also consider the case in which the two nations are separated (S).

\section{Description of agreements}

\subsection{Separated nations}

When the two nations are separated, we assume that there are neither international migration flows nor transfers from one nation to the other nation. The expected utility nation A would obtain in this case is

$$
E_{\mathrm{A}}^{\mathrm{S}}=\pi U(\rho)+(1-\pi) U(1)
$$

and the expected utility of nation $\mathrm{B}$ is

$$
E_{\mathrm{B}}^{\mathrm{S}}=(1-\pi) U(\rho)+\pi U(1) .
$$

These are the minimum utility levels that nations should obtain in order for them to be willing to participate in any other possible arrangement.

\subsection{Global union}

Given our assumptions, in a supranational unitary state (consisting of the union of nations $\mathrm{A}$ and $\mathrm{B}$ or of the union of regions $\mathrm{A} 1, \mathrm{~A} 2, \mathrm{~B} 1$ and $\mathrm{B} 2)$ the level of transfers is such that each region would end up with the same per capita income, $(\rho+1) / 2$ with certainty. Therefore, the expected utility for each region, or nation, would be

$$
U^{U}=U\left(\frac{\rho+1}{2}\right) .
$$

Thus, under the global union, there is complete sharing of resources and all agents obtain the same utility.

\subsection{Federation of nations}

The analysis in this section follows directly from Bucovetsky's analysis of a federation between two nations. The players are nation A and nation B. Since a nation is the union of two regions, the per capita income within a nation is the same for all agents, regardless of their residency. Thus, all agents in an independent nation in the good state of nature (state $\mathrm{H}$ ) would obtain the income level $\rho$, while in the bad state of nature (state L), they would obtain the income level 1 .

Under a federation of nation $\mathrm{A}$ and nation $\mathrm{B}$ agents are able to migrate within the federation. Some agents from the nation in the bad state of nature will migrate to the other nation, where residents, regardless where they came from, equally share the total income $\rho$. The equilibrium migration condition (Eq. (4) in Bucovetsky) is

$$
\frac{\rho}{1+n_{\mathrm{n}}}-c=\frac{1}{1-n_{\mathrm{n}}}
$$


where $n_{\mathrm{n}}$ is the net flow of migrants from the unlucky to the lucky nation. This condition means that per capita income in the lucky nation net of migration costs should equal that of the unlucky nation. This should hold for the marginal migrant. We will denote by $C_{j}$ per capita income, after migration takes place, for residents in a nation in the $j$ state of nature, $j \in\{\mathrm{H}, \mathrm{L}\}$. This means that the above condition could be written as

$$
C_{\mathrm{H}}-c=C_{\mathrm{L}} \text {. }
$$

Expected utility under the federation of nations for the rich nation $\mathrm{A}$ is

$$
\mathrm{EU}_{\mathrm{A}}^{\mathrm{FN}}=\pi U\left(C_{\mathrm{H}}\right)+(1-\pi) U\left(C_{\mathrm{L}}\right)
$$

and for $\mathrm{B}$, the poor nation, expected utility is

$$
\mathrm{EU}_{\mathrm{B}}^{\mathrm{FN}}=(1-\pi) U\left(C_{\mathrm{H}}\right)+\pi U\left(C_{\mathrm{L}}\right) .
$$

Note that existence of a strictly positive migration cost prevents from full equalization of income levels across nations. Original residents of a nation in state of nature $\mathrm{H}$ end up with an income level greater than the one obtained by agents from the other nation. And, clearly, all agents from the nation with the state of nature L obtain the same net income, i.e. the ones that migrate to the rich nation obtain the same (net) income as the ones that do not migrate. In the extreme case of no migration costs, $c=0$, the income of all agents would be equalized and a federation would coincide with a union of nations.

Since a centralized nation always equalizes the income across its regions it is natural to assume that the immigration flow $n_{\mathrm{n}}$ is equally shared by the two regions conforming the nation. $^{12}$ Thus, under the scenario $\mathrm{FN}$ each region of the lucky nation receives the migration flow $\left(n_{\mathrm{n}} / 2\right)$.

\subsection{Federation of regions}

Now we suppose that the decision makers are the regions. The agreement to be analyzed here is the federation of the all four regions (FR). We do not consider the possibility of a partial federation of two or three regions. It is also important to notice that our analysis of a federation of regions is not equivalent to the analysis of a federation of four "smaller" nations, because the two regions of a nation share a "national shock" in their resources.

Under a federation, agents are free to migrate from one region to another. There are no transfers so that the vector of total income levels obtained by the regions after the realization of the national and regional shocks is $\left\{Y_{\mathrm{HH}}, Y_{\mathrm{HL}}, Y_{\mathrm{LH}}, Y_{\mathrm{LL}}\right\}$. In this case, the migration equilibrium is more difficult to characterize. The difficulties come from the fact that, in principle, migration could take place among any combination of regions.

It is clear, however, that there is always migration from the unlucky region in the unlucky nation to the lucky region in the lucky nation. In this case, a necessary condition for migration equilibrium is

$$
\frac{Y_{\mathrm{HH}}}{1 / 2+n_{\mathrm{HH}}}-c=\frac{Y_{\mathrm{LL}}}{1 / 2-n_{\mathrm{LL}}}
$$

where $n_{\mathrm{LL}}$ is the flow of migrants from the unlucky region in the unlucky nation and $n_{\mathrm{HH}}$ the total flow of immigrants to the lucky region in the lucky nation. Denoting by $C_{i j}$ per

\footnotetext{
12 This assumption is introduced to simplify the analysis and the main results of the paper do not depend on it.
} 
capita consumption in the region with state of nature $i j$, we could rewrite the above expression as $C_{\mathrm{HH}}-c=C_{\mathrm{LL}}$.

Let $\mathrm{EU}_{z}^{\mathrm{FR}}$ be the expected utility under the federation of regions for region $z, z \in\{\mathrm{A} 1$, $\mathrm{A} 2, \mathrm{~B} 1, \mathrm{~B} 2\}$. One can show that under a federation of regions the expected utility for A1 is higher than the expected utility for any other region. More precisely

$$
\mathrm{EU}_{\mathrm{A} 1}^{\mathrm{FR}} \geq \mathrm{EU}_{z}^{\mathrm{FR}}, \quad z \in\{\mathrm{A} 2, \mathrm{~B} 1, \mathrm{~B} 2\} .
$$

This is an important inequality which will be used when comparing the federation and the union of regions and it is easily obtained by an standard application of first order stochastic dominance.

\section{The national versus the regional economy}

In this section we start comparing the economy with regions as the decision makers with the economy with nations as the decision makers. Let $c^{\mathrm{m}}$ be the lowest value of the migration cost such that none wants to migrate under the FN arrangement. We want to consider cases in which migration flows are positive, so we will assume migration costs lower than $c^{\mathrm{m}}$.

The first of our results shows that per capita income for the region in state $\mathrm{HH}$ and for the region in LL, after the migration flows have taken place, is smaller in the federation of regions than in the federation of nations. That is:

Lemma 1. Let (A.1) and (A.2) hold. Let $c<c^{m}$. Then, i) $C_{H H}<C_{H}$, ii) $C_{L L}<C_{L}$.

The intuition behind this result is that the dispersion of per capita incomes is larger in the economy with fiscally autonomous regions and this yields more migration and the lucky region in the lucky nation receives more immigration in the federation of regions (FR) than in the federation of nations (FN). It follows that the per capita income of that region is lower under FR than under FN.

Our second result regarding the economy with regions is that the expected utility of the richest region, A1, in FR is increasing with the difference between its expected income and the expected income of region A2. That is, it is increasing in $p$.

Lemma 2. Let (A.1) and (A.2) hold. Let $0 \leq c<c^{m}$. Then $E U_{A 1}^{F R}$ is increasing in p (strictly increasing if $\left.0<c<c^{m}\right)$.

This Lemma will be useful to obtain our main results as it implies that increasing regional income dispersion increases the expected utility of the richest region in a federation of regions. However, the expected utility of that region in a federation of nations remains constant upon changes in regional income dispersion.

Bucovetsky (1998) shows that, for a degree of relative risk aversion $\beta>2,{ }^{13}$ the expected utility of a nation under a federation is a quasi-concave function of the migration

13 Following Shiller and Athanasoulis (1995), $\beta=3$ represents a "consensus by many who work in this topic". This is also the average of the estimates reported in Friend and Blume (1975). Therefore assuming $\beta>2$ is not an unrealistic assumption. See Campbell (1999) for a summary on the empirical evidence on the values of the coefficient of risk aversion. 
cost $c$. The third result states that the expected utility of a region under FR is also quasiconcave on $c$, for $c \geq 0$. Thus, we have ${ }^{14}$ :

Lemma 3. Let (A.1) and (A.2) hold. Let $0 \leq c<c^{m}$ and $\beta>2$. Then $\mathrm{EU}_{A 1}^{F R}$ is a quasiconcave function of $c$.

\section{When will regions prefer more integration than nations?}

We want to analyze the different incentives for fiscally autonomous regions and for centralized nations in forming a supranational Union or Federation. The poor nation, B, always prefers a union of nations UN to a federation of nations $F N$. This is due to the fact that under UN each nation gets the per capita income $(1+\rho) / 2$ for sure whereas in the FN regime B faces a lottery with expected value lower than $(1+\rho) / 2$. Nation A, however, might or might not prefer the union to the federal regime depending on the value of the different parameters of our economy. It might even be the case that A prefers separation to FN. To rule out this possibility, i.e. to guarantee what Bucovetsky calls Individual Rationality of the Union, we impose the following condition

(A.3). $\rho^{\beta-1} \geq \frac{\pi}{1-\pi}$.

It is easy to show that the above inequality implies $\mathrm{EU}_{\mathrm{A}}^{\mathrm{UN}} \geq \mathrm{EU}_{\mathrm{A}}^{\mathrm{S}} \cdot{ }^{15}$ In this case, both nations prefer the Union to Separation.

If nation A prefers UN to FN (and (A.3) holds so that UN is Individually Rational) we conclude that the Union of Nations is a Pareto dominant arrangement and, consequently, both nations should be in favor of it. If, on the contrary, A prefers FN to UN then the two nations have different interests and the Union of Nations is less likely to be implemented than in the previous case.

The goal is to characterize in which cases fiscally autonomous regions (centralized nations) would unanimously agree on forming a Union, while, if the players were centralized nations (fiscally autonomous regions), only the poor nation (region) would be in favor of the Union.

Let the migration cost take the value $c$ and the probability that a rich region gets the lucky state be $p$. From now on we explicitly write the expected utility as a function of $c$ and $p$. For example, we write $\operatorname{EU}_{\mathrm{A}}^{\mathrm{FN}}(c)$ and $\operatorname{EU}_{R_{j}}^{\mathrm{FR}}(c, p) .{ }^{16}$

We write $\mathrm{UR}(c, p) \succ \mathrm{UN}(c)$ if at $(c, p)$ a Union is Pareto superior to a Federation for the regions, but not for the nations. In the case in which the Union is Pareto superior to a Federation for the regions and for the nations we write $\operatorname{UR}(c, p) \sim \mathrm{UN}(c)$. We also write $\mathrm{UR}(c, p) \sim \mathrm{UN}(c)$ to denote the case in which a Union is not Pareto superior for either the

\footnotetext{
14 The proof is inspired in the technics used by Bucovetsky. In our case, however, the possibility of many migration flows makes the proof more complex and elaborated.

${ }^{15}$ See Bucovetsky (1998).

${ }^{16}$ The first expression does not contain $p$ since the expected utility for nations is independent of such probability.
} 
nations or for the regions. We write $\operatorname{UR}(c, p) \succeq \mathrm{UN}(c)$ when either $\succ$ or $\sim$ holds or, equivalently, when $\operatorname{UN}(c) \succ \operatorname{UR}(c, p)$ does not hold. This motivates the following definition.

Definition. We say that, for a given value of $p$, a Union is more likely to be implemented when the regions are the players than when the nations are the players, and write $\mathrm{UR}(p) \succeq \mathrm{UN}$, whenever $\mathrm{UR}(c, p) \succeq \mathrm{UN}(c)$ for all $c$ (in the opposite case we write $\mathrm{UN} \succeq \operatorname{UR}(p))$.

Therefore, when the economy is such that $\operatorname{UR}(p) \succeq \mathrm{UN}$ we can say that the regions are more favorable to form a Union than the nations. Note that $\operatorname{UR}(p) \succeq \mathrm{UN}$ might hold for some, but not all, values of $p$. Next we state our main result.

Proposition 1. Let (A.1)-(A.3) hold. Let $0 \leq c<c^{m}$ and $\beta>2$. Then there exists a level of $p^{*}, 1 / 2 \leq p^{*} \leq 1$, such that we have $U R(p) \succeq U N$ for $p<p^{*}$ and $U N \succeq U R(p)$ for $p \geq p^{*}$. Moreover, if $\pi /(1-\pi)>\rho$ we know that $p^{*}>1 / 2$, and $Y_{L H} \geq(1+\rho) / 2$ is a suficient condition for $p^{*}<1$. The cut-off value $p^{*}$ is independent of $c$.

Sketch of the Proof. Consider the case in which UN is not always a Pareto dominant regime (the general case is analyzed in the formal proof provided in the Appendix). In Figs. 1 and 2, we show expected utilities of the richest nation and the richest region, as function of the migration costs, for the federation regime and the global union. In the formal proof we show that for $p$ close to $1 / 2$ (case represented in Fig. 1), expected utility of A1 in the FR intersects the expected utility level $\mathrm{EU}^{\mathrm{U}}$ at a lower value of $c$ (we call it $c$ ) than the value $\bar{c}$ at which expected utility of $\mathrm{A}$ in the $\mathrm{FN}$ intersects the level $\mathrm{EU}^{\mathrm{U}}$.

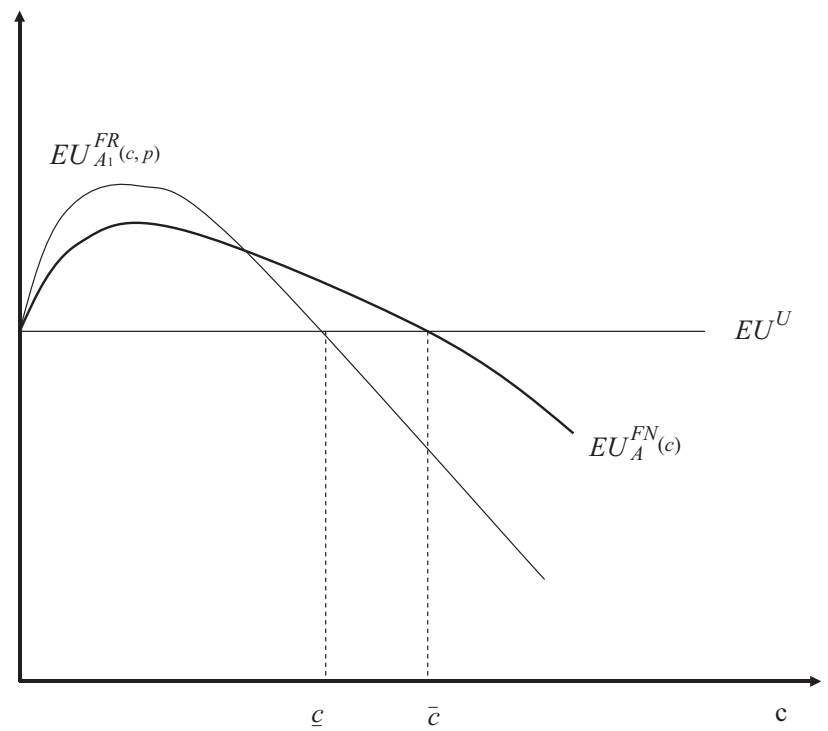

Fig. 1. Expected utilities of the richest nation and the richest region. 


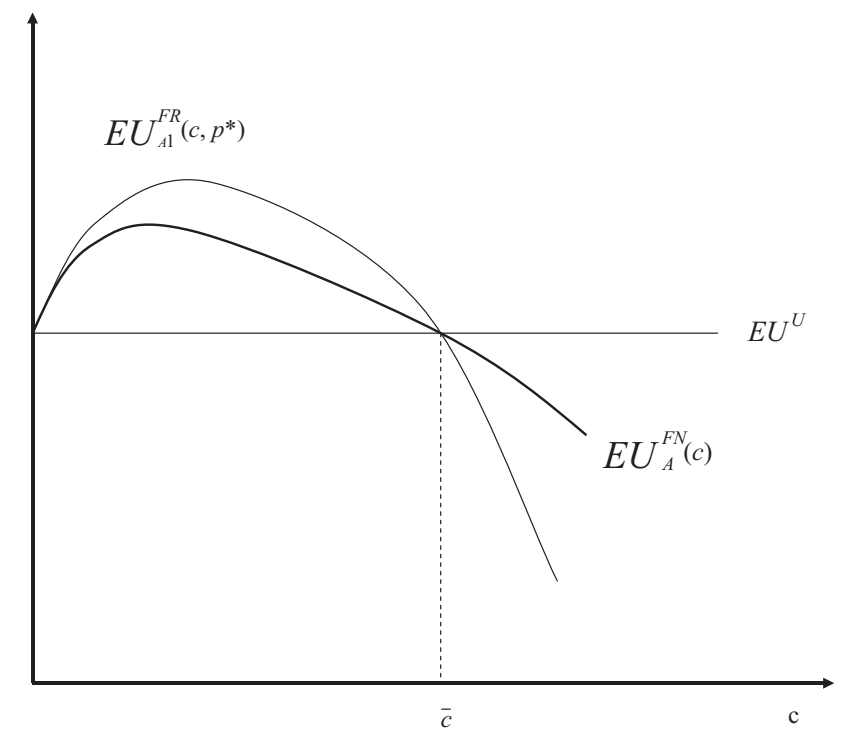

Fig. 2. Expected utilities of the richest nation and the richest region. The cut-off value $p^{*}$.

Therefore, for all $c$ in $(\underline{c}, \bar{c})$ we know that $\mathrm{EU}_{\mathrm{A}}^{\mathrm{FN}}(c)>\mathrm{EU}^{\mathrm{U}} \geq \mathrm{EU}_{\mathrm{A} 1}^{\mathrm{FR}}(c, p)$. For the rest of values for $c$ either $\mathrm{EU}_{\mathrm{A}}^{\mathrm{FN}}(c)>\mathrm{EU}^{\mathrm{U}}$ and $\mathrm{EU}_{\mathrm{A} 1}^{\mathrm{FR}}(c, p)>\mathrm{EU}^{\mathrm{U}}$ (for $c<\underline{c}$ ) or $\mathrm{EU}_{\mathrm{A}}^{\mathrm{FN}}(c)<\mathrm{EU}^{\mathrm{U}}$ and $\mathrm{EU}_{\mathrm{A} 1}^{\mathrm{FR}}(c, p)<\mathrm{EU}^{\mathrm{U}}$ (for $\left.c>\bar{c}\right)$.

We know, by Lemma 2, that expected utility of the richest region in FR is increasing with $p$. However, expected utility of the richest nation does not depend on $p$. Therefore one could intuitively think that, as $p$ increases, $\mathrm{EU}^{\mathrm{FR}}{ }_{\mathrm{A} 1}(c, p)$ shifts and that for some level of $p$ large enough the situation in Fig. 1 could be reversed, so that for all $c$ in an interval we have $\mathrm{EU}_{\mathrm{A}}{ }^{\mathrm{FN}}(c)<\mathrm{EU}^{\mathrm{U}} \leq \mathrm{EU}^{\mathrm{FR}}{ }_{\mathrm{A} 1}(c, p)$. We show in the formal proof that this reversal happens for $p$ smaller than 1 .

Given that $\mathrm{EU}^{\mathrm{FR}}{ }_{\mathrm{A} 1}(c, p)$ is strictly increasing in $p$ it is also easy to show that there is a cut-off value $p^{*}$ such that this reversal happens. This cut-off value is the one in Fig. 2 in which $\mathrm{EU}_{\mathrm{A} 1}^{\mathrm{FR}}\left(c, p^{*}\right)=\mathrm{EU}_{\mathrm{A}}{ }^{\mathrm{FN}}(c)=\mathrm{EU}^{\mathrm{U}}$ holds for one $c$. From our reasoning, it is easy to see that the cut-off value $p^{*}$ lies between $1 / 2$ and 1 .

Thus when the regions of a nation are similar enough to each other in expected terms (small values of $p$ ) we claim that a global union is more likely to be achieved when the players are fiscally autonomous regions than when the players are centralized nations. However, if the degree of diversity between regions in a nation is large enough (high values of $p$ ), then the opposite result is true. This result could be interpreted as saying that fiscally autonomous regions have more incentives than centralized nations to form a full global union when regional risk-sharing is the main reason for a fiscal agreement and the associated cost in terms of redistribution among regions is not that important. When, on the other hand, the income differences between the poor and the rich regions are very important (high values of $p$ ), achieving more integration is easier if nations are the decision makers. Notice that when $p$ is high the inter-regional transfers in a 
centralized nation can be seen more as pure redistribution than as risk-sharing between regions.

We cannot exclude the possibility that both nations and regions consider instrumenting transfers (see Bucovetsky, 1998 for a good discussion of transfers in this type of economy) that replicate an agreement closer to a union than to a federation. Given that migration takes resources, in case separation is not preferred to federation and union, there will always be a transfer scheme in which there are enough transfers to prevent any migration and some extra resources (the cost of migration) are distributed among the regions or nations. However, this type of efficiency enhancing transfer has to be made ex post to the realization of uncertainty and they would not change the nature of our economic conclusions in terms of the fiscal integration achieved.

The type of transfers that we will discuss in the next paragraphs are ex ante transfers, i.e. implemented before the realization of the state of nature, and the nations (or regions) could agree on them and on the type of fiscal agreement at the same time.

Consider the case $\underline{c}<c<\bar{c}$ and $p<p^{*}$ (a similar argument can be made for $p>p^{*}$ ) and suppose that a Union is not always a Pareto dominant regime for the nations. Here all regions prefer a unitary agreement to a federation whereas only the poor nation prefers the union to the federation. One can consider the possibility of an intermediate agreement where the two nations form a "Union" but with some additional transfers. In this case, some transfers have to be made from the poor to the rich country (which prefers a Federation to a Union) and so a "full Union" would not be achieved. Thus, in this case, our results are robust to the introduction of additional transfers between nations or regions.

In the case $c<\underline{c}$ both the poor region and the poor nation prefer a situation in which a Union is achieved and both are willing to make a positive transfer or "fee" to the rich region or to the rich nation, respectively. In that case, the amount of the transfer needed would be negatively correlated with the degree of integration achieved. I.e., full integration is achieved when that transfer is zero and no integration is achieved when the transfer is such that there is no expected net transfer from the rich area to the poor area. We may consider the minimum transfer needed to convince a rich nation to be part of a Union. Define $C^{*}$ as the solution to $U(C)=\mathrm{EU}_{\mathrm{A}}^{\mathrm{FN}}$ (i.e. the certainty equivalent to a federation from the point of view of nation $\mathrm{A}$ ). Then, nation B would need to pay to nation A a "fee" of at least $C^{*}-(1+\rho) / 2$ to convince it to form a Union. In that case, nation $\mathrm{A}$ is exactly as well off as in a Federation. Then to compare the maximum integration achieved in the economy with nations with the integration achieved in the economy with regions, we can calculate the certainty equivalents to a federation in each case. The economy with a larger certainty equivalent will result in less integration, as it requires a higher fee and consequently a lower amount of net transfers. Just looking at Fig. 1 one can see that which fee is higher depends on the parameters of the model. For migration costs high enough (although lower than $\underline{c}$ ) one has $\mathrm{EU}_{\mathrm{A}}^{\mathrm{FN}} \geq \mathrm{EU}_{\mathrm{A} 1}^{\mathrm{FR}}$ (this is a general result that is provided in the proof of the proposition), so in the economy of centralized nations a higher fee is needed and consequently less integration is obtained. However, as the example of Fig. 1 shows, for low enough migration costs the opposite result would be obtained. This means that only for low enough migration costs our results may not be robust to introduction of ex ante transfers. 


\section{Final comments}

We have analyzed the circumstances under which two centralized nations would choose a supranational fiscal agreement implying different integration levels than the fiscal agreement that would have been chosen by the regions forming those nations, if the regions were given enough fiscal autonomy. Our analysis yields some interesting political conclusions about the role of fiscally autonomous regions versus centralized nations in the formation of supranational economic areas. The claim that autonomous regions have more incentives than centralized nations to form a full global union is likely to be correct when nations are economic stable arrangements, i.e. when $p$ is low so that it is in the interests of the rich region to be part of a centralized nation. In this case, regional risk-sharing is the main reason for a national fiscal agreement and the associated cost in terms of redistribution among regions is not that important. When, on the other hand, it is not on the interest of a rich region to be part of a nation (high values of $p$ ), achieving a full supranational union will be easier if nations are the decision makers. Thus, the claim that regions have stronger incentives than nations to form a supranational union might be true only in the case regions have also strong incentives to be part of a centralized nation.

An interesting situation that has not been explicitly analyzed in this paper is the one in which A1, the richest region, prefers separation both to a federation of regions and to a union. In this case, it might also happen that region A1 would be better off on its own than as a member of nation A. It is easy to see that this is more likely to happen when $p$ is very high. Thus, since in this case the union with A2 was not in its interest, one can think of region A1 as been "forced", by non-economic reasons, to be member of nation A. Therefore, when the original nations are sustained by non-economic reasons, were their regions asked, the richest regions could even choose separation to any other fiscal agreement. We should not conclude, however, that whenever the nations are more in favor of the supranational union than the regions, i.e. whenever $\operatorname{UR}(p) \prec \mathrm{UN}$ happens, the richest region is being forced to be part of its nation, since it is easy to provide numerical examples for which $p$ is high and the rich region is better off being part of its nation than on its own and still $\operatorname{UR}(p) \prec \mathrm{UN}$.

We have not considered the possibility of a partial union or federation of one, two, or three regions. If this type of agreements were considered, a federation or a union of the three richer regions, excluding the poorest one, would always be preferred by those three regions to a federation or union of the four regions.

We have used a very simple model with a representative agent in each region. It is true that with heterogeneous agents migration and transfers have very different effects on welfare. It could happen that migration redistributes risk among the population in a nation (or region) in such a way that it is always a worse risk-sharing device than the one provided by transfers (see Wildasin, 1995). The analysis of a model with heterogeneous agents is left for future research.

\section{Acknowledgments}

We are grateful to S. Bucovetsky, K. Desmet, D. Wildasin and two anonymous referees for useful comments and suggestions. Ortuno-Ortin gratefully acknowledges financial 
support from Spanish Ministry of Science and Technology, Project SEJ2004-00968, Fundacion BBVA-3-04x and CAM 06/HSE/0157/2004.

\section{Appendix A}

Proof of Lemma 1. We first make the three following remarks about the consumption equilibrium values:

a) $C_{\mathrm{HH}}-c=C_{\mathrm{LL}} ; C_{\mathrm{H}}-c=C_{\mathrm{L}}$

b) $N_{\mathrm{HH}} C_{\mathrm{HH}}+N_{\mathrm{HL}} C_{\mathrm{HL}}+N_{L L} C_{L L}+N_{L H} C_{L H}=C_{H}+C_{L}$

c) $C_{\mathrm{LH}} \geq C_{\mathrm{LL}}$

where $N_{i j}$ stands for the total population in region $i j$ under the FR equilibrium. Part a) was already explained in the description of the possible agreements. Part b) states that the total income in the FR case and in the UN case is the same. Inequality c) follows from the fact that the income in LH is greater than in LL and the agents in region LH can always "imitate" what agents in region LL do, i.e., agents in LH start with a higher income than agents in LL and cannot end up, after migration flows take place, with a lower income than agents in LL.

The proof of statement i) is divided in two parts depending on the magnitude of $\gamma$. The statement in ii) follows easily from the first statement and remark a).

PART A. Suppose that $1+\gamma \leq \rho-\gamma$

There are two cases depending on the nature of the migration flows.

(1) Consider first the case in which regions $\mathrm{HH}$ and HL both receive immigrants at equilibrium.

It is clear that the income per capita must be the same in both regions, i.e. $C_{\mathrm{HH}}=C_{\mathrm{HL}}$, otherwise the last immigrants in the region with lower income per capita would had been better off by migrating to the other region. Suppose that $C_{\mathrm{HH}}>C_{\mathrm{H}}$ Then we also have that $C_{\mathrm{HL}}>C_{\mathrm{H}}$. By the equality in observation a) we have that $C_{L L}>C_{L}$. This inequality and c) imply that $C_{L H}>C_{L}$. Thus, in the FR case the per capita income in each region is higher than the corresponding national per capita income in the UN case. It is not difficult to see that in this case equality b) cannot hold. It follows that $C_{H H} \leq C_{H}$.

(2) Consider now the case in which only region $\mathrm{HH}$ receives immigrants at equilibrium.

a) We first prove that migration must go from region $\mathrm{LL}$ to region $\mathrm{HH}$ i.e., there is no migration from region LH. Suppose to the contrary. In this case, there would be migration from regions LL and $\mathrm{LH}$ to region $\mathrm{HH}$. Let $n_{\mathrm{HH}}$ be the total number of immigrants received by $\mathrm{HH}$. It helps to imagine migration as a process in which first all immigrants are from the poorest region, LL. When the level of migration is high enough the per capita income in LL reaches the level of per capita income in 
$\mathrm{LH}$, and from that moment on there is also migration from the region LH. It is clear that always exists such a number of immigrants from region LL that makes the per capita income in both regions equal, i.e. there exists $n \leq n_{\mathrm{HH}}$ such that

$$
1+\gamma=\frac{1-\gamma}{1-2 n}
$$

We want to show that for such a level of immigrants, $n$, the per capita income in region $\mathrm{HH}$ is lower or equal than the per capita income in region HL. To see it, suppose the contrary so that

$$
\frac{\rho+\gamma}{1+n}>\rho-\gamma
$$

Solving from $n$ in equality Eq. (7) we get $n=2 \gamma /(1+\gamma)$. Then inequality Eq. (8) can be written as

$$
\frac{\rho+\gamma}{1+\frac{2 \gamma}{1+\gamma}}>\rho-\gamma
$$

or

$$
\rho<\frac{\frac{2 \gamma^{2}}{1+\gamma}+2 \gamma}{\frac{2 \gamma}{1+\gamma}}
$$

and inequality Eq. (9) implies

$$
\rho<1+2 \gamma
$$

which contradicts the first assumption on this Part A) of the proof.

b) The result above showed that the migration flow goes from region LL to region $\mathrm{HH}$. Thus, none in region LH migrates.

The equilibrium migration under $\mathrm{FN}$ is given by condition Eq. (2)

$$
\frac{\rho}{1+n_{\mathrm{n}}}-c=\frac{1}{1-n_{\mathrm{n}}}
$$

and the equilibrium migration under FR is given by condition Eq. (5), that can be written as

$$
\frac{(\rho+\gamma)}{1+2 n_{\mathrm{r}}}-c=\frac{(1-\gamma)}{1-2 n_{\mathrm{r}}}
$$

Assuming our particular value of $\gamma \leq(\rho-1) / 2$, and by simply comparing the numerators of condition Eq. (2) and the modified condition Eq. ( $\left.5^{\prime}\right)$, we conclude that $2 n_{\mathrm{r}}>n_{\mathrm{n}}$. Recall that it was assumed that the in the UN case region $\mathrm{HH}$ gets $\left(n_{\mathrm{n}}\right) / 2$ immigrants. Thus, the number of immigrants that region $\mathrm{HH}$ gets in the FR case, $n_{\mathrm{r}}$, is higher than what it gets under $\mathrm{UN},\left(n_{\mathrm{n}}\right) / 2$. 
In this particular case, the total per-capita income to be distributed between the region in state of nature $\mathrm{HH}$ and the region in state of nature LL (and also in nations $\mathrm{H}$ and $\mathrm{L}$ ) is $(1+\rho) / 2$. Thus, we have the identity

$$
C_{\mathrm{HH}} N_{\mathrm{HH}}+C_{\mathrm{LL}}\left(1-N_{\mathrm{HH}}\right)=(1+\rho) / 2
$$

where 1 is the total population of the two regions and $N_{\mathrm{HH}}$ the percentage of that total living in the region in state of nature $\mathrm{HH}$, $0 \leq N_{\mathrm{HH}} \leq 1$. Since $C_{\mathrm{HH}}-c=C_{\mathrm{LL}}$ we also have

$$
C_{\mathrm{HH}} N_{\mathrm{HH}}+\left(C_{\mathrm{HH}}-c\right)\left(1-N_{\mathrm{HH}}\right)=(1+\rho) / 2
$$

so $C_{\mathrm{HH}}=(1+\rho) / 2+c\left(1-N_{\mathrm{HH}}\right)$. The same identity holds for $C_{\mathrm{H}}, C_{\mathrm{L}}$ and $N_{\mathrm{H}}$. Thus, per-capita income in the region in state $\mathrm{HH}$ increases as the population of the other region increases. That is, it decreases with migration. This implies that in the federation of regions, where migration to the region in state $\mathrm{HH}$ is higher than under the federation of nations, the region in state $\mathrm{HH}$ ends up with a lower level of per capita income than under the federation of nations.

PART B. Suppose that $1+\gamma>\rho-\gamma$.

This part is proven by similar steps to the ones in Part A and we omit it. It only requires to realize that now, regarding to the migration flows, region LH plays a similar role to region $\mathrm{HL}$ in the previous part.

Proof of Lemma 2. We have that

$$
\mathrm{EU}_{\mathrm{A} 1}^{\mathrm{FR}}(p)=\pi\left(p U\left(C_{\mathrm{HH}}\right)+(1-p) U\left(C_{\mathrm{HL}}\right)\right)+(1-\pi)\left(p U\left(C_{\mathrm{LH}}\right)+(1-p) U\left(C_{\mathrm{LL}}\right)\right)
$$

We want to show that $\frac{\mathrm{dEU}_{\mathrm{Al}}^{\mathrm{FR}}(p)}{\mathrm{d} p}$ is positive. Recalling that $C_{\mathrm{HH}} \geq C_{\mathrm{HL}}$ and $C_{\mathrm{LH}} \geq C_{\mathrm{LL}}$, we conclude that,

$$
\frac{\mathrm{dEU}_{\mathrm{A} 1}^{\mathrm{FR}}(p)}{\mathrm{d} p}=\pi\left(U\left(C_{\mathrm{HH}}\right)-U\left(C_{\mathrm{HL}}\right)\right)+(1-\pi)\left(U\left(C_{\mathrm{LH}}\right)-U\left(C_{\mathrm{LL}}\right)\right) 0 .
$$

When $c>0$ at least one of the previous inequalities has to be strict so that $\frac{\mathrm{dEU}_{\mathrm{Al}}^{\mathrm{FR}}(p)}{\mathrm{d} p}>0$.

Proof of Lemma 3. We consider the case in which regions $\mathrm{HH}$ and HL both receive immigrants from regions LL and LH. The rest of cases can be proven in a similar way by setting the corresponding migration values equal to zero.

It has been shown in the Proof of Lemma 1 that when HH and HL both receive migrants the per capita consumption in region $\mathrm{HH}$ has to be equal to the per capita consumption in region HL. Let $n_{\mathrm{HH}}$ be the number of immigrants in region $\mathrm{HH}$ and $n_{\mathrm{HL}}$ the number of immigrants in region HL. At equilibrium we have

$$
C_{\mathrm{HH}} \equiv \frac{Y_{\mathrm{HH}}}{\frac{1}{2}+n_{\mathrm{HH}}}=\frac{Y_{\mathrm{HL}}}{\frac{1}{2}+n_{\mathrm{HL}}} \equiv C_{\mathrm{HL}}
$$


It follows from Eq. (10) that

$$
n_{\mathrm{HH}}=\frac{Y_{\mathrm{HH}}-Y_{\mathrm{HL}}}{2}+\frac{Y_{\mathrm{HH}}}{Y_{\mathrm{HL}}} n_{\mathrm{HL}} .
$$

It is easy to see that if there is migration from region LL and from region LH the consumption (per capita) in these two regions must be the same. Let $n_{\mathrm{HH}}$ denote the migration from $\mathrm{HH}$ and $n_{\mathrm{HL}}$ the migration from LH. At equilibrium we have

$$
C_{\mathrm{LL}} \equiv \frac{Y_{\mathrm{LL}}}{\frac{1}{2}-n_{\mathrm{LL}}}=\frac{Y_{\mathrm{LH}}}{\frac{1}{2}-n_{\mathrm{LH}}} \equiv C_{\mathrm{LH}}
$$

so that

$$
n_{\mathrm{LL}}=\frac{Y_{\mathrm{LH}}-Y_{\mathrm{LL}}}{2}+\frac{Y_{\mathrm{LL}}}{Y_{\mathrm{LH}}} n_{\mathrm{LH}}
$$

It follows from Eq. (11) and Eq. (13) that

$$
n_{\mathrm{HH}}^{\prime}=\frac{Y_{\mathrm{HH}}}{Y_{\mathrm{HL}}} n_{\mathrm{HL}}^{\prime} ; \quad n_{\mathrm{HH}}^{\prime \prime}=\frac{Y_{\mathrm{HH}}}{Y_{\mathrm{HL}}} n_{\mathrm{HL}}^{\prime \prime}
$$

and

$$
n_{\mathrm{LL}}^{\prime}=\frac{Y_{\mathrm{LL}}}{Y_{\mathrm{LH}}} n_{\mathrm{LH}}^{\prime} ; \quad n_{\mathrm{LL}}^{\prime \prime}=\frac{Y_{\mathrm{LL}}}{Y_{\mathrm{LH}}} n_{\mathrm{LH}}^{\prime \prime}
$$

We also have that

$$
n_{\mathrm{HH}}+n_{\mathrm{HL}}=n_{\mathrm{LL}}+n_{\mathrm{LH}}
$$

which, together with Eq. (14) and Eq. (15), imply

$$
n_{\mathrm{HL}}^{\prime}=k n_{\mathrm{LH}}^{\prime}
$$

and

$$
n_{\mathrm{HL}}^{\prime \prime}=k n_{\mathrm{LH}}^{\prime \prime}
$$

where $k=\left(\frac{Y_{\mathrm{LL}}+Y_{\mathrm{LH}}}{Y_{\mathrm{LH}}}\right) /\left(\frac{Y_{\mathrm{HL}}+Y_{\mathrm{HH}}}{Y_{\mathrm{HL}}}\right)$.

From the definitions of $\mathrm{EU}_{\mathrm{A} 1}^{\mathrm{FR}}, C_{\mathrm{HH}}, C_{\mathrm{HL}}, C_{\mathrm{LH}}$ and $C_{\mathrm{LL}}$ we have that

$$
\begin{aligned}
\frac{\partial \mathrm{EU}_{\mathrm{A} 1}^{\mathrm{FR}}}{\partial c}= & -\pi p U^{\prime}\left(C_{\mathrm{HH}}\right) \frac{n_{\mathrm{HH}}^{\prime} Y_{\mathrm{HH}}}{\left[\frac{1}{2}-n_{\mathrm{HH}}\right]^{2}}-\pi(1-p) U^{\prime}\left(C_{\mathrm{HL}}\right) \frac{n_{\mathrm{HL}}^{\prime} Y_{\mathrm{HL}}}{\left[\frac{1}{2}+n_{\mathrm{HL}}\right]^{2}} \\
& +(1-\pi)(1-p) U^{\prime}\left(C_{\mathrm{LL}}\right) \frac{n_{\mathrm{LL}}^{\prime} Y_{\mathrm{LL}}}{\left[\frac{1}{2}-n_{\mathrm{LL}}\right]^{2}}+(1-\pi) p U^{\prime}\left(C_{\mathrm{LH}}\right) \frac{n_{\mathrm{LH}}^{\prime} Y_{\mathrm{LH}}}{\left[\frac{1}{2}-n_{\mathrm{LH}}\right]^{2}}
\end{aligned}
$$


Differentiating again with respect to $c$

$$
\begin{aligned}
\frac{\partial^{2} \mathrm{EU}_{\mathrm{A} 1}^{\mathrm{FR}}}{\partial c^{2}}= & A+\pi p\left(U^{\prime \prime}\left(C_{\mathrm{HH}}\right) \frac{\left(n_{\mathrm{HH}}^{\prime} Y_{\mathrm{HH}}\right)^{2}}{\left[\frac{1}{2}+n_{\mathrm{HH}}\right]^{2}}+U^{\prime}\left(C_{\mathrm{HH}}\right) \frac{2\left(n_{\mathrm{HH}}^{\prime}\right)^{2} Y_{\mathrm{HH}}}{\left[\frac{1}{2}+n_{\mathrm{HH}}\right]^{3}}\right) \\
& +\pi(1-p)\left(U^{\prime \prime}\left(C_{\mathrm{HL}}\right) \frac{\left(n_{\mathrm{HL}}^{\prime} Y_{\mathrm{HL}}\right)^{2}}{\left[\frac{1}{2}+n_{\mathrm{HL}}\right]^{2}}+U^{\prime}\left(C_{\mathrm{HL}}\right) \frac{2\left(n_{\mathrm{HL}}^{\prime}\right)^{2} Y_{\mathrm{HL}}}{\left[\frac{1}{2}+n_{\mathrm{HL}}\right]^{3}}\right)^{\prime \prime}(1-p)\left(U^{\prime \prime}\left(C_{\mathrm{LL}}\right) \frac{\left(n_{\mathrm{LL}}^{\prime} Y_{\mathrm{LL}}\right)^{2}}{\left[\frac{1}{2}-n_{\mathrm{LL}}\right]^{2}}+U^{\prime}\left(C_{\mathrm{LL}}\right) \frac{2\left(n_{\mathrm{LL}}^{\prime}\right)^{2} Y_{\mathrm{LL}}}{\left[\frac{1}{2}-n_{\mathrm{LL}}\right]^{3}}\right. \\
& +(1-\pi) \\
& +(1-\pi) p\left(U^{\prime \prime}\left(C_{\mathrm{LH}}\right) \frac{\left(n_{\mathrm{LH}}^{\prime} Y_{\mathrm{LH}}\right)^{2}}{\left.\left[\frac{1}{2}-n_{\mathrm{LH}}\right]^{2}+U^{\prime}\left(C_{\mathrm{LH}}\right) \frac{2\left(n_{\mathrm{LH}}^{\prime}\right)^{2} Y_{\mathrm{LH}}}{\left[\frac{1}{2}-n_{\mathrm{LH}}\right]^{3}}\right]^{[}}\right.
\end{aligned}
$$

where

$$
\begin{aligned}
A \equiv-\pi p U^{\prime}\left(C_{\mathrm{HH}}\right) \frac{n_{\mathrm{HH}}^{\prime \prime} Y_{\mathrm{HH}}}{\left[\frac{1}{2}+n_{\mathrm{HH}}\right]^{2}}-\pi(1-p) U^{\prime}\left(C_{\mathrm{HL}}\right) \frac{n_{\mathrm{HL}}^{\prime \prime} Y_{\mathrm{HL}}}{\left[\frac{1}{2}+n_{\mathrm{HL}}\right]^{2}} \\
+(1-\pi)(1-p) U^{\prime}\left(C_{\mathrm{LL}}\right) \frac{n_{\mathrm{LL}}^{\prime \prime} Y_{\mathrm{LL}}}{\left[\frac{1}{2}-n_{\mathrm{LL}}\right]^{2}}+(1-\pi) p U^{\prime}\left(C_{\mathrm{LH}}\right) \frac{n_{\mathrm{LH}}^{\prime \prime} Y_{\mathrm{LH}}}{\left[\frac{1}{2}-n_{\mathrm{LH}}\right]^{2}}
\end{aligned}
$$

and by equalities Eqs. (10), (11), (14) and Eq. (18) we can rewrite A as

$$
\begin{aligned}
A \equiv-\pi U^{\prime}\left(C_{\mathrm{HH}}\right)\left(p \frac{\frac{Y_{\mathrm{HH}}}{Y_{\mathrm{HL}}} Y_{\mathrm{HH}}}{\left[\frac{1}{2}+n_{\mathrm{HH}}\right]^{2}}+(1-p) \frac{Y_{\mathrm{HL}}}{\left[\frac{1}{2}+n_{\mathrm{HL}}\right]^{2}}\right) k n_{\mathrm{LH}}^{\prime \prime} \\
+(1-\pi) U^{\prime}\left(C_{\mathrm{LL}}\right)\left((1-p) \frac{\frac{Y_{\mathrm{LL}}}{Y_{\mathrm{LL}}}}{\left[\frac{1}{2}-n_{\mathrm{LL}}\right]^{2}}+p \frac{Y_{\mathrm{LH}}}{\left[\frac{1}{2}-n_{\mathrm{LH}}\right]^{2}}\right) n_{\mathrm{LH}}^{\prime \prime}
\end{aligned}
$$


and Eq. (19) can be rewritten as

$$
\begin{aligned}
\frac{\partial \mathrm{EU}_{\mathrm{A} 1}^{\mathrm{FR}}}{\partial}= & -\pi U^{\prime}\left(C_{\mathrm{HH}}\right)\left(p \frac{\frac{Y_{\mathrm{HH}}}{Y_{\mathrm{HL}}} Y_{\mathrm{HH}}}{\left[\frac{1}{2}+n_{\mathrm{HH}}\right]^{2}}+(1-p) \frac{Y_{\mathrm{HL}}}{\left[\frac{1}{2}+n_{\mathrm{HL}}\right]^{2}}\right) k n_{\mathrm{LH}}^{\prime} \\
& +(1-\pi) U^{\prime}\left(C_{\mathrm{LL}}\right)\left((1-p) \frac{\frac{Y_{\mathrm{LL}}}{Y_{\mathrm{LH}}} Y_{\mathrm{LL}}}{\left[\frac{1}{2}-n_{\mathrm{LL}}\right]^{2}}+p \frac{Y_{\mathrm{LH}}}{\left[\frac{1}{2}-n_{\mathrm{LH}}\right]^{2}}\right) n_{\mathrm{LH}}^{\prime}
\end{aligned}
$$

It follows from Eqs. (21) and (22) that

$$
A=\frac{\partial \mathrm{EU}_{\mathrm{A} 1}^{\mathrm{FR}}}{\partial c} \frac{n_{\mathrm{LH}}^{\prime \prime}}{n_{\mathrm{LH}}^{\prime}}
$$

$\underset{\partial \mathrm{EU}_{\mathrm{Al}}^{\mathrm{FR}}}{\text { Thus, whenever }} \frac{\partial \mathrm{EU}}{\partial c}=0$ we also have $\mathrm{A}=0$. It follows that at any $c$ such that $\frac{\partial \mathrm{EU}_{\mathrm{Al}}^{\mathrm{RR}}}{\partial c}=0$ Eq. (20) becomes

$$
\begin{aligned}
\frac{\partial^{2} \mathrm{EU}_{\mathrm{A} 1}^{\mathrm{FR}}}{\partial c^{2}}= & \pi U^{\prime \prime}\left(C_{\mathrm{HH}}\right)\left(p \frac{\left(n_{\mathrm{HH}}^{\prime}\right)^{2} Y_{\mathrm{HH}}^{2}}{\left[\frac{1}{2}+n_{\mathrm{HL}}\right]^{4}}+(1-p) \frac{\left(n_{\mathrm{HL}}^{\prime}\right)^{2} Y_{\mathrm{HL}}^{2}}{\left[\frac{1}{2}+n_{\mathrm{HL}}\right]^{4}}\right) \\
& +(1-\pi) U^{\prime \prime}\left(C_{\mathrm{LL}}\right)\left((1-p) \frac{\left(n_{\mathrm{LL}}^{\prime}\right)^{2} Y_{\mathrm{LL}}^{2}}{\left[\frac{1}{2}-n_{\mathrm{LL}}\right]^{2}}+p \frac{\left(n_{\mathrm{LH}}^{\prime}\right)^{2} Y_{\mathrm{LH}}^{2}}{\left[\frac{1}{2}-n_{\mathrm{LH}}\right]^{2}}\right) \\
& +\pi U^{\prime}\left(C_{\mathrm{HH}}\right)\left(p \frac{2\left(n_{\mathrm{HH}}^{\prime}\right)^{2} Y_{\mathrm{HH}}}{\left[\frac{1}{2}+(1-p) \frac{2\left(n_{\mathrm{HL}}^{\prime}\right)^{2} Y_{\mathrm{HL}}}{\left[\frac{1}{2}+n_{\mathrm{HL}}\right]^{3}}\right]^{3}}\right. \\
& +(1-\pi) U^{\prime}\left(C_{\mathrm{LL}}\right)\left((1-p) \frac{2\left(n_{\mathrm{LL}}^{\prime}\right)^{2} Y_{\mathrm{LL}}}{\left[\frac{1}{2}-n_{\mathrm{LL}}\right]^{3}}+p \frac{2\left(n_{\mathrm{LH}}^{\prime}\right)^{2} Y_{\mathrm{LH}}}{\left[\frac{1}{2}-n_{\mathrm{LH}}\right]^{3}}\right)
\end{aligned}
$$


where we have used the fact that at equilibrium $C_{\mathrm{HH}}=C_{\mathrm{HL}}$ and $C_{\mathrm{LL}}=C_{\mathrm{LH}}$. From the fact that $\beta=\frac{U^{\prime \prime}(x)}{U^{\prime}(x)} x$ for all $\boldsymbol{x}$, and from Eqs. (14) and (15) we can rewrite Eq. (24) as

$$
\begin{aligned}
\frac{\partial^{2} \mathrm{EU}_{\mathrm{Al}}^{\mathrm{FR}}}{\partial c^{2}}=(2-\beta)\left(\left(n_{\mathrm{HL}}^{\prime}\right)^{2} \pi U^{\prime}\left(C_{\mathrm{HH}}\right)\left(p \frac{\left(\frac{Y_{\mathrm{HH}}}{Y_{\mathrm{HL}}}\right)^{2} C_{\mathrm{HH}}}{\left[\frac{1}{2}+n_{\mathrm{HH}}\right]^{2}}+(1-p) \frac{C_{\mathrm{HH}}}{\left[\frac{1}{2}+n_{\mathrm{HL}}\right]^{2}}\right)\right. \\
+\left(n_{\mathrm{LH}}^{\prime}\right)^{2}(1-\pi) U^{\prime}\left(C_{\mathrm{LH}}\right)\left(p \frac{\left(\frac{Y_{\mathrm{LL}}}{Y_{\mathrm{LH}}}\right)^{2} C_{\mathrm{LL}}}{\left[\frac{1}{2}-n_{\mathrm{LL}}\right]^{2}}+(1-p) \frac{C_{\mathrm{LL}}}{\left[\frac{1}{2}-n_{\mathrm{LH}}\right]^{2}}\right)
\end{aligned}
$$

By assumption $\beta>2$, so that Eq. (25) is negative. It follows that $\frac{\partial^{2} \mathrm{EU}_{\mathrm{Al}}^{\mathrm{RR}}}{\partial c^{2}}<0$ at any $c$ such that $\frac{\partial \mathrm{EU}_{\mathrm{A}}^{\mathrm{FR}}}{\partial c}=0$ which implies that $\mathrm{EU}_{\mathrm{A} 1}^{\mathrm{FR}}$ is quasi-concave.

Proof of the Proposition. If the value of $\rho$ is too large it might happen that, for all positive values of the migration $\operatorname{cost} c$, a federation is a worse insurance device for nation $\mathrm{A}$ than a union so that $\mathrm{EU}^{\mathrm{U}} \geq \mathrm{EU}_{\mathrm{A}}^{\mathrm{FN}}$. The following condition implies that there exists values of $c$ for which such inequality is not true so that $\mathrm{UN}$ is not always a Pareto dominant regime, ${ }^{17}$

$$
\frac{\pi}{1-\pi} \rho \text {. }
$$

Thus we will divide the proof of the theorem in two cases. The first will be the one in which this condition is satisfied. The second will consider the case in which UN is always Pareto dominant for the nations.

1) Assume $\frac{\pi}{1-\pi} \geq \rho$ is satisfied.

We will show that for small values of $p, \mathrm{UR}(p) \succ \mathrm{UN}$ is satisfied whereas for large values of $p$, $\mathrm{UN} \succ \mathrm{UR}(p)$ is satisfied. Then a continuity argument will close the proof.

1.a) Consider the extreme case with $p=1 / 2$.

We first show that there exists a $\underline{c}$ and a $\bar{c}$ so that for every $c \in(\underline{c}, \bar{c})$ we have $\mathrm{UR}(c, 1 / 2) \succ \mathrm{UN}(c)$. Recall that $\mathrm{EU}^{\mathrm{U}}=U\left(\frac{1+\rho}{2}\right)$. Thus $\mathrm{UR}(c, 1 / 2) \succ \mathrm{UN}(c)$ iff the inequalities

$$
\mathrm{EU}_{\mathrm{A}}^{\mathrm{FN}}(c)>U\left(\frac{1+\rho}{2}\right)
$$

and

$$
\mathrm{EU}_{R_{j}}^{\mathrm{FR}}\left(c, \frac{1}{2}\right) \leq U\left(\frac{1+\rho}{2}\right) \quad \text { for all } R_{j}
$$

hold simultaneously.

By the inequalities given in Eq. (6) we know that Eq. (27) is equivalent to

$$
\mathrm{EU}_{\mathrm{A} 1}^{\mathrm{FR}}\left(c, \frac{1}{2}\right) \leq U\left(\frac{1+\rho}{2}\right) \text {. }
$$

\footnotetext{
${ }^{17}$ See Bucovetsky for the proof of this claim.
} 
Let $\bar{c}>0$ be such that

$$
\mathrm{EU}_{\mathrm{A}}^{\mathrm{FN}}(\bar{c})=U\left(\frac{1+\rho}{2}\right) \text {. }
$$

Existence of $\bar{c}$ follows from: a) $\mathrm{EU}_{\mathrm{A}}^{\mathrm{FN}}(0)=\mathrm{EU}^{\mathrm{U}}$; b) for $c^{\mathrm{m}}$ we have $\mathrm{EU}_{\mathrm{A}}^{\mathrm{FN}}\left(c^{\mathrm{m}}\right)=\mathrm{EU}_{\mathrm{A}}^{\mathrm{S}}$; c) by (A.3) $\mathrm{EU}^{\mathrm{U}}>\mathrm{EU}_{\mathrm{A}}^{\mathrm{S}}$; d) by continuity of $\mathrm{EU}_{\mathrm{A}}^{\mathrm{FN}}(c)$ and; e) since $\frac{\pi}{1-\pi} \geq \rho$ there exists $c^{\sim}$ such that $\mathrm{EU}_{\mathrm{A}}{ }^{\mathrm{FN}}\left(c^{\sim}\right)>\mathrm{EU}^{\mathrm{U}}$ (see Fig. 1).

If such $\bar{c}$ is not unique take the infimum of them. Also realize that condition $\frac{\pi}{1-\pi} \geq \rho$ guarantees that $\bar{c}>0$.

We can write

$$
\mathrm{EU}_{\mathrm{A}}^{\mathrm{FN}}(\bar{c})=\pi U\left(\bar{C}_{\mathrm{H}}\right)+(1-\pi) U\left(\bar{C}_{\mathrm{L}}\right)
$$

where $\bar{C}_{\mathrm{H}}$ and $\bar{C}_{\mathrm{L}}$ are the equilibrium per capita income levels when the migration cost is $\bar{c}$. For that $\bar{c}$ and for $p=1 / 2$ we write the expected utility for region A1 in FR as

$$
\mathrm{EU}_{\mathrm{A} 1}^{\mathrm{FR}}\left(\bar{c}, \frac{1}{2}\right)=\frac{1}{2} \pi\left(U\left(\bar{C}_{\mathrm{HH}}\right)+U\left(\bar{C}_{\mathrm{HL}}\right)\right)+\frac{1}{2}(1-\pi)\left(U\left(\bar{C}_{\mathrm{LL}}\right)+U\left(\bar{C}_{\mathrm{LH}}\right)\right)
$$

so that inequality Eq. (28) holds, for $\bar{c}$ and $p=1 / 2$, if

$$
\frac{1}{2}\left(\pi\left(U\left(\bar{C}_{\mathrm{HH}}\right)+U\left(\bar{C}_{\mathrm{HL}}\right)\right)+(1-\pi)\left(U\left(\bar{C}_{\mathrm{LL}}\right)+U\left(\bar{C}_{\mathrm{LH}}\right)\right)\right)<U\left(\frac{1+\rho}{2}\right) .
$$

Lemma 1 states that $C_{\mathrm{L}}>C_{\mathrm{LL}}$ and $C_{\mathrm{H}}>C_{\mathrm{HH}}$. It follows that

$$
\frac{1}{2}\left(\pi U\left(\bar{C}_{\mathrm{HH}}\right)+(1-\pi) U\left(\bar{C}_{\mathrm{LL}}\right)\right)<\frac{1}{2}\left(\pi U\left(\bar{C}_{\mathrm{H}}\right)+(1-\pi) U\left(\bar{C}_{\mathrm{L}}\right)\right)
$$

and from Eqs. (29) and (30) we have

$$
\frac{1}{2}\left(\pi U\left(\bar{C}_{\mathrm{H}}\right)+(1-\pi) U\left(\bar{C}_{\mathrm{L}}\right)\right)=\frac{1}{2} U\left(\frac{1+\rho}{2}\right) .
$$

It follows that

$$
\frac{1}{2}\left(\pi U\left(\bar{C}_{\mathrm{HH}}\right)+(1-\pi) U\left(\bar{C}_{\mathrm{LL}}\right)\right)<\frac{1}{2} U\left(\frac{1+\rho}{2}\right) .
$$

The next step is to show that

$$
\frac{1}{2}\left(\pi U\left(\bar{C}_{\mathrm{HL}}\right)+(1-\pi) U\left(\bar{C}_{\mathrm{LH}}\right)\right)<\frac{1}{2} U\left(\frac{1+\rho}{2}\right) .
$$

If there is no migration in regions $\mathrm{HL}$ and $\mathrm{LH}$ we have that $\bar{C}_{\mathrm{HL}}=\frac{Y_{\mathrm{HL}}}{\frac{1}{2}}, \bar{C}_{\mathrm{LH}}=\frac{Y_{\mathrm{LH}}}{\frac{1}{2}}$ so that $\bar{C}_{\mathrm{HL}}+\bar{C}_{\mathrm{LH}}=\frac{1+\rho}{2}$. Since $U$ is concave it follows that Eq. (36) holds. If there is only migration to region $\mathrm{HL}$ we have that $\bar{C}_{\mathrm{HL}}<\frac{Y_{\mathrm{HL}}}{\frac{1}{2}}$ and by the previous argument we again obtain that Eq. (36) holds. It was showed in the proof of Lemma 3 that the only remaining possibility is that there is migration from region $\mathrm{LH}$ and migration to region HL. In this case, consumption must be such that $\bar{C}_{\mathrm{HL}}=\bar{C}_{\mathrm{HH}}$ and $\bar{C}_{\mathrm{LL}}=\bar{C}_{\mathrm{LH}}$ and by Eq. (35) we again have that inequality Eq. (36) holds. Summing up, we have shown that Eqs. (35) and (36) always hold. 
Thus Eqs. (35) and (36) imply that Eq. (32) is true and, as a consequence, Eqs. (28) and (27) also hold for $\bar{c}$ and $p=1 / 2$.

By continuity of $\mathrm{EU}_{\mathrm{A} 1}^{\mathrm{FR}}(\boldsymbol{c}, 1 / 2)$, for a set of values of $c$ smaller than $\bar{c}$ we have that Eq. (27) holds true. It only rests to show that for values of $c$ close enough to $\bar{c}$ and $c<\bar{c}$ we have that Eq. (26) is true, i.e. $\operatorname{EU}_{\mathrm{A}}^{\mathrm{FN}}(c)>U\left(\frac{1+\rho}{2}\right)$. Since $\operatorname{EU}_{\mathrm{A}}^{\mathrm{FN}}(c)$ is continuous at $\bar{c}$ we only need to show that $\mathrm{EU}_{\mathrm{A}}^{\mathrm{FN}}(c)$ is decreasing at $\bar{c}$. But this follows from observations a) - e) above. Summing up: we have shown that there exists a set $\left(c^{\prime}, \bar{c}\right)$ of values of $c$ that satisfy Eqs. (26) and (27) simultaneously, i.e. for all $c \in\left(c^{\prime}, \bar{c}\right)$ we have $\operatorname{UR}(c, 1 / 2) \succ \mathrm{UN}(c)$.

Let $\underline{c}$ be defined as follows

$$
\underline{c}=\inf \left\{c: \mathrm{EU}_{\mathrm{A} 1}^{\mathrm{FR}}\left(c, \frac{1}{2}\right)=U\left(\frac{1+\rho}{2}\right)\right\} .
$$

By the argument given above we know that $\mathrm{EU}_{\mathrm{A} 1}^{\mathrm{FR}}\left(\bar{c}, \frac{1}{2}\right)<U\left(\frac{1+\rho}{2}\right)$ and we also have that $\mathrm{EU}_{\mathrm{A} 1}^{\mathrm{FR}}\left(0, \frac{1}{2}\right)=U\left(\frac{1+\rho}{2}\right)$. Then, quasi-concavity of $\mathrm{EU}_{\mathrm{A} 1}^{\mathrm{FR}}(c, 1 / 2)$ implies that $\underline{c}<\bar{c}$. Quasi-concavity also implies that for all $c \in(\underline{c}, \bar{c})$ we have $\operatorname{EU}_{\mathrm{A} 1}^{\mathrm{FR}}\left(c, \frac{1}{2}\right) \leq$ $\bar{U}\left(\frac{1+\rho}{2}\right)$. Remember that we already showed that $\mathrm{EU}_{\mathrm{A}}^{\mathrm{FN}}(c)>U\left(\frac{1+\rho}{2}\right)$ for all $0<c<\underline{c}$. Therefore we have $\operatorname{UR}(c, 1 / 2) \succ \mathrm{UN}(c)$ for all $c \in(\underline{c}, \bar{c})$.

Next, we show that $\operatorname{UR}(c, 1 / 2) \sim \mathrm{UN}(c)$ for all $c \in /(\underline{c}, \bar{c})$. Quasi-concavity of the functions $\mathrm{EU}_{\mathrm{A} 1}^{\mathrm{FR}}(c, 1 / 2)$ and $\mathrm{EU}_{\mathrm{A}}^{\mathrm{FN}}(c)$ and the fact that both of them are decreasing at $\bar{c}$ imply that $\mathrm{EU}_{\mathrm{A} 1}^{\mathrm{FR}}\left(c, \frac{1}{2}\right)<U\left(\frac{1+\rho}{2}\right)$ for all $c>\bar{c}$ and $\mathrm{EU}_{\mathrm{A}}^{\mathrm{FN}}(c) \leq U\left(\frac{1+\rho}{2}\right)$ for all $c>\bar{c}$. In this case, a Union is Pareto efficient for both the regions and the nations. Hence we have $\operatorname{UR}(c, 1 / 2) \sim \mathrm{UN}(c)$ for all $c>\bar{c}$.

The definition of $\underline{c}$ and the equalities $\operatorname{EU}_{\mathrm{A} 1}^{\mathrm{FR}}\left(0, \frac{1}{2}\right)=\mathrm{EU}_{\mathrm{A}}^{\mathrm{FN}}(0)=U\left(\frac{1+\rho}{2}\right)$ and quasi-concavity of these functions imply that $\mathrm{EU}_{\mathrm{A} 1}^{\mathrm{FR}}\left(c, \frac{1}{2}\right)>U\left(\frac{1+\rho}{2}\right)$ for all $c<\underline{c}$ and $\mathrm{EU}_{\mathrm{A}}^{\mathrm{FN}}(c)>U\left(\frac{1+\rho}{2}\right)$ for all $c<\underline{c}$. Hence, a Union is not Pareto superior to a Federation neither for the regions nor for the nations and we have $\operatorname{UR}(c, 1 / 2) \sim \mathrm{UN}(c)$ for all $c<\underline{c}$.

A continuity argument can be used to show that for values of $p>1 / 2$ and close enough to $1 / 2$, we still have $\operatorname{UR}(p) \succ \mathrm{UN}$.

1.b) Now consider the limit case in which $p=1$. We have

$$
\mathrm{EU}_{\mathrm{A} 1}^{\mathrm{FR}}(c, 1)=\pi U\left(C_{\mathrm{HH}}\right)+(1-\pi) U\left(C_{\mathrm{LH}}\right) .
$$

We want to compare $\mathrm{EU}_{\mathrm{Al}}^{\mathrm{FR}}(\bar{c}, 1)$ to $\mathrm{EU}^{\mathrm{U}}$ where the value $\bar{c}$ is the one given in section 1.a) above By the reasoning in Lemma 1, we know that $C_{\mathrm{HH}}>C_{\mathrm{LH}}$. Two cases must be considered:

i) $Y_{\mathrm{LH}} \geq \frac{1+\rho}{2}$. In this case, it is easy to see that $C_{\mathrm{HH}}>\frac{1+\rho}{2}$ and $C_{\mathrm{LH}} \geq \frac{1+\rho}{2}$ (otherwise the total resources wouldn't add up to $1+\rho$ ). It follows that $\operatorname{EU}_{\mathrm{A} 1}^{\mathrm{FR}}(\bar{c}$, 1) $>\mathrm{EU}^{\mathrm{U}}$ for every $c \geq 0$. Thus, in this case, a Union is never Pareto superior to a Federation for the regions. However $\operatorname{EU}_{\mathrm{A}}^{\mathrm{FN}}(c)$ is independent of $p$, and we know that $\mathrm{EU}_{\mathrm{A}}^{\mathrm{FN}}(c) \leq \mathrm{EU}^{\mathrm{U}}$ for all $c>\bar{c}$ and $\mathrm{EU}_{\mathrm{A}}^{\mathrm{FN}}(c)>\mathrm{EU}^{\mathrm{U}}$ for all $c<\bar{c}$.

ii) $Y_{\mathrm{LH}}<\frac{1+\rho}{2}$. We still have that $C_{\mathrm{HH}}>\frac{1+\rho}{2}$; however, one can easily show that now $C_{\mathrm{LH}} \leq \frac{1+\rho}{2}$. Thus, in principle we could have $\operatorname{EU}_{\mathrm{A} 1}^{\mathrm{FR}}(\bar{c}, 1)<\mathrm{EU}^{\mathrm{U}}$.

1.c) $\mathrm{EU}_{\boldsymbol{A} 1}^{\mathrm{FR}}$ is continuous in $p$ and, by Lemma 2, is also strictly increasing in $p$. Then, existence of $p^{*}>1.2$ easily follows from result in section 1.a). 
Let $\tilde{p}$ be the solution to $\mathrm{EU}_{\mathrm{A} 1}^{\mathrm{FR}}(\bar{c}, p)=\mathrm{EU}_{\mathrm{A}}^{\mathrm{FN}}(\bar{c})$, where $\bar{c}$ is the one defined in section 1.a). It is easy to check that $p^{*}$ is given by $\operatorname{Min}\left\{1, p^{\sim}\right\}$ (see Fig. 2). Notice that two cases are possible. When the condition in part i) of section 1.b) holds we have that $p^{*}=\tilde{p}<1$. When part ii) of such condition holds it might happen that $\tilde{p}>1$ and in that case $p^{*}=1$. Thus, we know that a sufficient condition for $p^{*<1}$ is that $Y_{\mathrm{LH}} \geq \frac{1+\rho}{2}$.

2) Assume now that UN is always Pareto dominant for the nations, i.e. $\frac{\pi}{1-\pi}<\rho$.

For $c=0$ a Union will give the same expected utility as that of any kind of Federation. Therefore, for costless migration $\mathrm{EU}_{\mathrm{A} 1}^{\mathrm{FR}}(0, p)=\mathrm{EU}_{\mathrm{A}}^{\mathrm{FN}}(0)=\mathrm{EU}^{\mathrm{U}}$. Since $\mathrm{EU}_{\mathrm{A}}^{\mathrm{FN}}(c) \leq \mathrm{EU}^{\mathrm{U}}$ for all $c \geq 0$, quasi-concavity of $\mathrm{EU}_{\mathrm{A}}^{\mathrm{FN}}(c)$ implies that $\mathrm{EU}_{\mathrm{A}}^{\mathrm{FN}}(c)$ is decreasing. $\operatorname{If~}_{\operatorname{EU}}^{\mathrm{FR}}(c, p)$ is increasing (decreasing) in $c$ at $c=0$, by quasi-concavity, we have $\mathrm{UN} \succeq \operatorname{UR}(p)$ (UN UR $(p)$ ). Thus, we need to show that there exists $p^{*}$ such that for all $p<p^{*}$ the function $\operatorname{EU}_{\mathrm{A} 1}^{\mathrm{FR}}(0, p)$ is decreasing in $c$, and for $p>p^{*}$ the function $\operatorname{EU}_{\mathrm{A} 1}^{\mathrm{FR}}(0, p)$ is increasing in $c$.

From the definitions of $\mathrm{EU}_{\mathrm{A} 1}^{\mathrm{FR}}, C_{\mathrm{HH}}, C_{\mathrm{HL}}$ and $C_{\mathrm{LL}}$,

$$
\begin{aligned}
\frac{\partial \mathrm{EU}_{\mathrm{Al}}^{\mathrm{FR}}(0, p)}{\partial c}= & -\pi U^{\prime}\left(C_{\mathrm{HH}}\right)\left(p \frac{\frac{Y_{\mathrm{HH}}}{Y_{\mathrm{HL}}} Y_{\mathrm{HH}}}{\left[\frac{1}{2}+n_{\mathrm{HH}}\right]^{2}}+(1-p) \frac{Y_{\mathrm{HL}}}{\left[\frac{1}{2}+n_{\mathrm{HL}}\right]^{2}}\right) k n_{\mathrm{LH}}^{\prime} \\
& +(1-\pi) U^{\prime}\left(C_{\mathrm{LL}}\right)\left((1-p) \frac{\frac{Y_{\mathrm{LL}}}{Y_{\mathrm{LH}}} Y_{\mathrm{LL}}}{\left[\frac{1}{2}-n_{\mathrm{LL}}\right]^{2}}+p \frac{Y_{\mathrm{LH}}}{\left[\frac{1}{2}-n_{\mathrm{LH}}\right]^{2}}\right) n_{\mathrm{LH} \cdot}^{\prime}
\end{aligned}
$$

However, when $c=0$ we know that free migration leads to

$$
C_{\mathrm{HH}}=C_{\mathrm{HL}}=C_{\mathrm{LH}}=C_{\mathrm{LL}}
$$

which is equivalent to

$$
\frac{Y_{\mathrm{HH}}}{\frac{1}{2}+n_{\mathrm{HH}}}=\frac{Y_{\mathrm{HL}}}{\frac{1}{2}+n_{\mathrm{HL}}}=\frac{Y_{\mathrm{LH}}}{\frac{1}{2}-n_{\mathrm{LH}}}=\frac{Y_{\mathrm{LL}}}{\frac{1}{2}-n_{\mathrm{LL}}} .
$$

This implies that we could write Eq. (22) as

$$
\begin{aligned}
\frac{\partial \mathrm{EU}_{\mathrm{A} 1}^{\mathrm{FR}}(0, p)}{\partial c}= & n_{\mathrm{LH}}^{\prime} U^{\prime}\left(C_{\mathrm{HH}}\right) C_{\mathrm{HH}}\left(\frac{-\pi p \frac{Y_{\mathrm{HH}}}{Y_{\mathrm{HL}}}}{\frac{1}{2}+n_{\mathrm{HH}}}+\pi(1-p) \frac{k}{\frac{1}{2}+n_{\mathrm{HL}}}\right. \\
& +(1-\pi)(1-p) \frac{\left.\frac{Y_{\mathrm{LL}}}{\frac{Y_{\mathrm{LH}}}{2}-n_{\mathrm{LL}}}+(1-\pi) p \frac{1}{\frac{1}{2}-n_{\mathrm{LH}}}\right) .}{} .
\end{aligned}
$$


Consider the case where $p=1$ :

$$
\frac{\partial \mathrm{EU}_{\mathrm{A} 1}^{\mathrm{FR}}(0,1)}{\partial c}=n_{\mathrm{LH}}^{\prime}(c) U^{\prime}\left(C_{\mathrm{HH}}\right) C_{\mathrm{HH}}\left(\frac{-\pi \frac{Y_{\mathrm{HH}}}{Y_{\mathrm{HL}}}}{\frac{1}{2}+n_{\mathrm{HH}}}+(1-\pi) \frac{1}{\frac{1}{2}-n_{\mathrm{LH}}}\right) .
$$

Given that $n_{\mathrm{LH}}^{\prime}(c) \leq 0, \pi>1 / 2$ and by the equalities in Eq. (39) this derivative is always positive.

Now consider the extreme case where $p=1 / 2$, so

$$
\begin{aligned}
\frac{\partial \mathrm{EU}_{\mathrm{Al}}^{\mathrm{FR}}\left(0, \frac{1}{2}\right)}{\partial c}= & n_{\mathrm{LH}}^{\prime}(c) U^{\prime}\left(C_{\mathrm{HH}}\right) C_{\mathrm{HH}} \frac{1}{2}\left(\frac{-\pi \frac{Y_{\mathrm{HH}}}{Y_{\mathrm{HL}}}}{\frac{1}{2}+n_{\mathrm{HH}}}+(1-\pi) \frac{1}{\frac{1}{2}-n_{\mathrm{LH}}}\right. \\
& \left.-\pi \frac{k}{\frac{1}{2}+n_{\mathrm{HL}}}+(1-\pi) \frac{\frac{Y_{\mathrm{LL}}}{Y_{\mathrm{LH}}}}{\frac{1}{2}-n_{\mathrm{LL}}}\right) .
\end{aligned}
$$

The sign of the above derivative is not determined. However, from Eqs. (41) and (42) we know that

$$
\frac{\partial \mathrm{EU}_{\mathrm{A} 1}^{\mathrm{FR}}(0,1)}{\partial c}>\frac{\partial \mathrm{EU}}{\mathrm{AR}\left(0, \frac{1}{2}\right)}
$$

iff

$$
-\pi \frac{k}{\frac{1}{2}+n_{\mathrm{HL}}}+(1-\pi) \frac{\frac{Y_{\mathrm{LL}}}{Y_{\mathrm{LH}}}}{\frac{1}{2}-n_{\mathrm{LL}}}>0 .
$$

Since $k=\frac{Y_{\mathrm{HL}}}{\rho Y_{\mathrm{LH}}}$ and by the equalities in Eq. (39), inequality Eq. (44) is equivalent to

$$
\frac{(1-\pi)}{\pi}>\frac{1}{\rho}
$$

and by the first assumption in this part of the proof Eq. (45) always holds. Thus, inequality Eq. (43) also holds.

Lemma 2, inequality Eq. (43) and that fact that the utility function is continuous as a function of $p$ and $c$ are enough to guarantee the existence of $p^{*}$ such that: i) if $\frac{\partial \mathrm{EU}_{\mathrm{Al}}^{\mathrm{FR}}\left(0, \frac{1}{2}\right)}{\partial c} \geq$

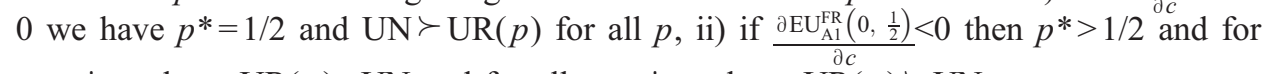
$p \leq p *$ we have $\mathrm{UR}(p) \sim \mathrm{UN}$ and for all $p>p *$ we have $\mathrm{UR}(p) \succ \mathrm{UN}$.

\section{References}

Alesina, A., Perotti, R., 1998. Economic risk and political risk in fiscal unions. Economic Journal 108, 989-1009. 
Alesina, A., Spolaroe, E., 1997. On the number and size of nations. Quarterly Journal of Economics 112 , $1027-1056$.

Asdrubali, P., Sorensen, B., Yosha, O., 1996. Channels of interstate risksharing: United States 1963-1990. Quarterly Journal of Economics 111, 1081-1110.

Athanasoulis, S., von Wincoop, E., 1998. Risksharing Within the United States, What Have Financial Markets and Fiscal Federalism Accomplished? Federal Reserve Bank of New York. (April).

Barro, R., Sala-i-Martin, X., 1991. Convergence across states and regions. Brookings Papers on Economic Activity $1,107-158$.

Barro, R., Sala-i-Martin, X., 1992. Regional growth and migration: a Japan-United States comparison. Journal of the Japanese and International Economies 6, 312-346.

Berkowitz, D., 1997. Regional income and secession: center-periphery relations in emerging market economies. Regional Science and Urban Economics 27 (1), 17-45.

Blanchard, O., Katz, L., 1992. Regional evolutions. Brookings Papers on Economic Activity 1, 1-61.

Bucovetsky, S., 1998. Federalism, equalization and risk aversion. Journal of Public Economics 67, $301-328$.

Campbell, J.Y., 1999. Asset prices, consumption, and the business cycle. In: Taylor, J.B., Woodford, M. (Eds.), Handbook of Macroeconomics, vol. 1c. Elsevier Science, Amsterdam, pp. 1231-1303.

Casella, A., 2001. The role of market size in the formation of jurisdictions. Review of Economic Studies 68 , $83-108$.

Eichengreen, B., 1993. Labor markets and European monetary unification. In: Masson, P., Taylor, M. (Eds.), Policy Issues in the Operation of Currency Unions. Cambridge University Press, London, pp. 130-162.

Esteban, J., 1994. La desigualdad interregional en Europa y en España: Descripción y análisis. In: Esteban, J., Vives, X. (Eds.), Crecimiento y Convergencia Regional en España y Europa, vol. 2. Institut d'Anàlisi Econòmica, Barcelona.

Forni, M., Reichlin, L., 1999. Risk and potential insurance in Europe. European Economic Review 43, 1237-1256.

Friend, I., Blume, M., 1975. The demand for risky assets. American Economic Review 65, 900-922.

Melitz, J., Zumer, F., 2002. Regional redistribution and stabilization by the center in Canada, France, the UK and the US: a reassessment and new tests. Journal of Public Economics 86, 263-286.

Obstfeld, M., 1994. Risk-taking, global diversification and growth. American Economic Review 84, 1310 - 1329.

Persson, T., Tabellini, G., 1996a. Federal fiscal constitutions: risk sharing and moral hazard. Econometrica 64, $623-646$.

Persson, T., Tabellini, G., 1996b. Federal fiscal constitutions: risk sharing and redistribution. Journal of Political Economy 104, 979-1009.

Sala-i-Martin, X., Sachs, J., 1992. Fiscal federalism and optimum currency areas: evidence for Europe from the United States. In: Canzoneri, M., Masson, P., Grilli, V. (Eds.), Establishing a Central Bank: Issues in Europe and Lessons from the U.S. Cambridge University Press, London, pp. 195-219.

Shiller, R., Athanasoulis, S., 1995. World income components: measuring and exploiting international risk sharing opportunities. National Bureau of Economic Research. (Working paper No. 5095).

Sorensen, B., Yosha, O., 1998. International risk sharing and European monetary unification. Journal of International Economics 45, 211-238.

van Wincoop, E., 1999. How big are the potential welfare gains from international risk sharing? Journal of International Economics 47, 109-135.

von Hagen, J., 1992. Fiscal arrangements in a monetary union — some evidence from the U.S. In: Fair, D., de Boissieu, C. (Eds.), Fiscal Policy, Taxes, and the Financial System in an Increasingly Integrated Europe. Kluwer Academic Press, Netherlands, pp. 337-360.

Wildasin, D., 1995. Factor mobility, risk and redistribution in the welfare state. Scandinavian Journal of Economics 97, 527-546.

Wildasin, D., 2000. Labor market integration, investment in risky human capital, and fiscal competition. American Economic Review 90, 73-95. 